\title{
Can Halophilic and Psychrophilic Microorganisms Modify the Freezing/Melting Curve of Cold Salty Solutions? Implications for Mars Habitability
}

\author{
Laura Garcia-Descalzo, ${ }^{1}$ Carolina Gil-Lozano,,2 Victoria Muñoz-Iglesias, ${ }^{1}$ \\ Olga Prieto-Ballesteros, ${ }^{1}$ Armando Azua-Bustos, ${ }^{1,3}$ and Alberto G. Fairén ${ }^{1,4}$
}

\begin{abstract}
We present the hypothesis that microorganisms can change the freezing/melting curve of cold salty solutions by protein expression, as it is known that proteins can affect the liquid-to-ice transition, an ability that could be of ecological advantage for organisms on Earth and on Mars. We tested our hypothesis by identifying a suitable candidate, the well-known psycrophile and halotolerant bacteria Rhodococcus sp. JG3, and analyzing its response in culture conditions that included specific hygroscopic salts relevant to Mars-that is, highly concentrated magnesium perchlorate solutions of $20 \mathrm{wt} \%$ and $50 \mathrm{wt} \% \mathrm{Mg}\left(\mathrm{ClO}_{4}\right)_{2}$ at both end members of the eutectic concentration (44 wt \%) - and subfreezing temperatures (263 K and $253 \mathrm{~K}$ ). Using a combination of techniques of molecular microbiology and aqueous geochemistry, we evaluated the potential roles of proteins over- or underexpressed as important players in different mechanisms for the adaptability of life to cold environments. We recorded the changes observed by micro-differential scanning calorimetry. Unfortunately, Rhodococcus sp. JG3 did not show our hypothesized effect on the melting characteristics of cold Mg-perchlorate solutions. However, the question remains as to whether our novel hypothesis that halophilic/psychrophilic bacteria or archaea can alter the freezing/melting curve of salt solutions could be validated. The null result obtained after analyzing just one case lays the foundation to continue the search for proteins produced by microorganisms that thrive in very cold, high-saline solutions, which would involve testing different microorganisms with different salt components. The immediate implications for the habitability of Mars are discussed. Key Words: Mars-ExtremophilesPerchlorates-Cold brines-Melting/freeze point-Calorimetry-Chaotropism. Astrobiology 20, 1067-1075.
\end{abstract}

\section{Introduction and Motivation}

$\mathbf{T}$ HE PRESENCE OF liquid water on Mars has been linked to a decrease in the freezing point of aqueous solutions by variable enrichment in dissolved salts such that high ionic solutions and brines would be prevalent on a "cool and wet" Mars (Fairén, 2010, 2020), a hypothesis that has found recent support in the identification of highly saline intervals in the Gale crater lakes (Rapin et al., 2019; Thomas et al., 2019). Perchlorate salts are of particular relevance to Mars. The discovery of perchlorates on Mars (Hecht et al., 2009; Glavin et al., 2013; Sutter et al., 2017) has significant astrobiological implications because (1) they are chaotropic salts, (2) they are highly hygroscopic, (3) in aqueous systems they have eutectics at subzero temperature, and (4) they can serve as electron acceptors for a number of microorganisms under anoxic conditions. These physical and chemical properties are key to the occurrence of liquid water under current cold and dry martian conditions and potentially in the past. Therefore, numerous studies have been conducted to investigate the stability of perchlorate salt solutions, which have been proposed to exist as metastable supersaturated solutions over a wide range of relative humidity $(\mathrm{RH})$ and temperature conditions relevant to Mars (Zorzano et al., 2009; Davila et al., 2010; Gough et al., 2011; Martín-Torres et al., 2015; Ojha et al., 2015). Among them, magnesium perchlorate is particularly relevant because the binary system has the eutectic point at $216 \mathrm{~K}$ (Supplementary Fig. S1) (Stillman and

\footnotetext{
${ }^{1}$ Centro de Astrobiología (CSIC-INTA), Madrid, Spain.

${ }^{2}$ Departamento de Geociencias Marinas, Universidad de Vigo, Vigo, Spain.

${ }^{3}$ Instituto de Ciencias Biomédicas, Facultad de Ciencias de la Salud, Universidad Autónoma de Chile, Santiago, Chile.

${ }^{4}$ Department of Astronomy, Cornell University, Ithaca, New York, USA.
}

(C) Laura Garcia-Descalzo et al., 2020; Published by Mary Ann Liebert, Inc. This Open Access article is distributed under the terms of the Creative Commons Attribution Noncommercial License (http://creativecommons.org/licenses/by-nc/4.0/) which permits any noncommercial use, distribution, and reproduction in any medium, provided the original author(s) and the source are credited. 
Grimm, 2011), and its hexahydrate solid-phase $\left[\mathrm{Mg}\left(\mathrm{ClO}_{4}\right)_{2}\right.$. $\left.6 \mathrm{H}_{2} \mathrm{O}\right]$ deliquesces above $40 \% \mathrm{RH}\left(\mathrm{a}_{\mathrm{w}}=0.4\right)$, forming films of liquid brines that appear to remain stable even at current Mars surface conditions (Chevrier et al., 2009; Robertson and Bish, 2011).

Defining a lower limit of water activity at which life can thrive has become a difficult task due to the continuous discoveries of extremophiles living at edge conditions. Recent work has shown that some halophiles can tolerate highly concentrated solutions of perchlorate (Oren et al., 2014; Al Soudi et al., 2017; Heinz et al., 2019). Regarding the adaptive strategies to freezing temperatures, several studies have indicated the ability of some microorganisms to modify the melting and freezing points of water, resulting in a gap between both points, known as thermal hysteresis (TH) (Celik et al., 2010; Raymond and Kim, 2012; Davies, 2014). Other microorganisms such as the well-known bacterial epiphyte of plants Pseudomonas syringae (Kajava et al., 1993) can reduce the supercooling point of water in plants and thereby enhance ice crystal formation at subzero temperatures and promote frost damage in the plant, which favors their own growth (Hirano and Upper, 2000). The iceminus variant of this bacterium is a mutant without the gene responsible for the production of the ice-nucleating surface protein, with several applications in biotechnology and frost prevention in crops (Cochet and Widehem, 2000). By these adaptive mechanisms, microorganisms create microenvironments of liquid water that provide a certain tolerance to cold solutions. The molecules responsible for this strategy are the ice-binding proteins (IBPs). IBPs are divided into two groups: the ice nucleation proteins that promote ice growth at significant subfreezing temperatures (Maki et al., 1974), and the antifreeze proteins (AFP or AP) that stop ice crystal growth by surface adsorption inhibition mechanisms (Raymond and DeVries, 1977). AFP/AP are responsible for preventing freezing inside an organism (Davies, 2014) in that they promote the thermodynamically less favorable microcurvature of the ice surface when bound to it (Knight, 2000).

The foundation of the hypothesis presented in this article is the precise testing of whether the molecules (mainly proteins) derived from the adaptations of microorganisms to cold salty conditions can influence their own environment. To test our hypothesis, we evaluated the relative survivability of Rhodococcus sp. JG3 and Escherichia coli on perchlorate solutions at subfreezing temperatures and explored whether the microorganisms exert any influence on the chemo-physical properties of aqueous environments relevant to Mars, as an adaptive response through molecular mechanisms (IBPs, cold shock proteins (Csp), membrane lipids, or others).

\section{Experimental Setting}

We established an experimental setting in which bacterial cultures were incubated in highly concentrated magnesium perchlorate solutions at two different subzero temperatures over the course of 10 days. Our technical approach involved the use of micro differential scanning calorimetry in the bacterial cultures to record potential changes in the liquidus curve of magnesium perchlorate solutions [20 wt \% and $\left.50 \mathrm{wt} \% \mathrm{Mg}\left(\mathrm{ClO}_{4}\right)_{2}\right]$ at both sides of the eutectic concentration $(44 \mathrm{wt} \%)$. Calorimetry is a primary technique that is useful in measuring the thermal properties of substances, and it is the model method for the direct determination of enthalpy in that it measures the heat flux derived from changes of chemical/physical properties recorded in a sample along with the temperature and/or time (Gill et al., 2010). Although calorimetry has been used to study isolated IBPs in aqueous solutions (Hansen and Baust, 1988; Lee et al., 2018), it has not, to the best of our knowledge, been applied to the analysis of changes in the melting/freezing behavior of perchlorate solutions that may be the result of the presence of whole bacterial cultures at subfreezing temperatures, which would imply a more complex and uncontrolled chemical system.

We chose the aerobic, eurypsychrophilic soil actinobacterium Rhodococcus sp. JG3, which was isolated from the permafrost of the hyperarid Upper Dry Valleys of Antarctica. We used an aerobic strain because growth rates in psychrophiles are faster for aerobes than for anaerobes. Rhodococcus sp. JG3 is also halotolerant (Goordial et al., 2015), and some species of the genus Rhodococcus have been reported to use IBPs (Lorv et al., 2014). To test the bacterial survivability and the potential molecules responsible for it, we also used cytometry techniques to distinguish between living cells and dead cells, as well as cell concentration in the cultures. We also used protein gel electrophoresis to compare protein profiles between optimal and stressing conditions of the selected bacteria. Our detailed Materials and Methods section is described in Section 1 of Supplementary Data.

\section{Results}

\subsection{Magnesium perchlorate solutions with presence of bacteria}

Calorimetry measures the variation of the heat flow in a sample with respect to temperature, signaling when a chemophysical change occurs, for example, freezing or melting (Supplementary Fig. S2). In our experiments, we were not able to reach the solidus temperature of the binary system due to the strong supercooling, but the liquidus was well constrained. When we cooled down to $123 \mathrm{~K}$ and then heated the system, we found only that the glass transition around $155 \mathrm{~K}$ [observed also by Toner et al. (2014)] prevented the observation of hypothetical solidus at 216 (Supplementary Fig. S2) and therefore prevented the start of the melting. To determine the liquidus temperature, we used the method of extrapolation at the zero heating rate (Gibout et al., 2018). Once we obtained the heat flow curve and divided it by the sample mass and the heating rate, we calculated the specific heat. The integration of this curve with respect to the temperature gives the enthalpy of the reaction related to the temperature $(\mathrm{H} / \mathrm{T})$. When the derivative curve is zero, the temperature would correspond with the melting of the last solid (liquidus temperature). On the contrary, TH was calculated by using the difference between the $\mathrm{T}_{\text {onset }}$ of the heat flow curve during freezing and the $\mathrm{T}_{\text {onset }}$ of the melting during heating.

In the absence of bacteria, the temperature of the liquidus curve of the magnesium perchlorate solution, indicated by the $\mathrm{dH} / \mathrm{dT}$, occurred at $265.53 \pm 0.12 \mathrm{~K}$ in the case of $20 \mathrm{wt} \% \mathrm{Mg}\left(\mathrm{ClO}_{4}\right)_{2}$. Replicated measurements of the sterile solution at $50 \mathrm{wt} \% \mathrm{Mg}\left(\mathrm{ClO}_{4}\right)_{2}$ settled the end 
of melting, when neither ice crystals nor remains of hydrated salts were present, at $311 \mathrm{~K}$.

In samples of Rhodococcus sp. JG3 cultures that were incubated for 10 days at $263 \mathrm{~K}$, we observed a slight change of $0.4 \mathrm{~K}$ in the liquidus curve of $20 \mathrm{wt} \% \mathrm{Mg}\left(\mathrm{ClO}_{4}\right)_{2}$ solution compared with the sterile solution, which unfortunately fell within the experimental error (Fig. 1A). Thus, we could not unequivocally relate this slight variation with the metabolism of the cells. When we repeated the experiment at $123 \mathrm{~K}$, no clear differences were detected either in the liquidus temperature between the initial cultures and the cultures after 10 days, although slight variations were observed when compared with the sterile solution. No noticeable results were obtained when using the $50 \mathrm{wt} \% \mathrm{Mg}\left(\mathrm{ClO}_{4}\right)_{2}$ solution. A relative depression in the liquidus point was somewhat detectable in E. coli cultures, although this appeared at a slightly higher temperature than was the case for the Rhodococcus cultures. There was an almost negligible difference, however, with regard to sterile solutions (Fig. 1A). This was also verified by the application of Levene's and Mann-Whitney-Wilcoxon tests (XLSTAT 2020, Addinsoft, for Microsoft Excel), which were used to compare means between groups and did not show significant differences as well. In particular, the $p$-value given by the Levene's test (0.039) compelled us to use a nonparametric post hoc test, the Mann-Whitney-Wilcoxon test, which is especially recommended for nonlarge groups of data. As indicated, this analysis did not reveal significant differences between groups as well. Considering the potential effect of the hypothetical presence of IBPs (and maybe by the effect of other molecules), we investigated the $\mathrm{TH}$ in $20 \mathrm{wt} \% \mathrm{Mg}\left(\mathrm{ClO}_{4}\right)_{2}$ samples with Rhodococcus cultures. We tried to determine whether there was a relationship between these data and the cell concentration of the cultures obtained by cytometry, but the tendency in this hypothetical relationship was not clear and would require additional experiments (Fig. 1B).

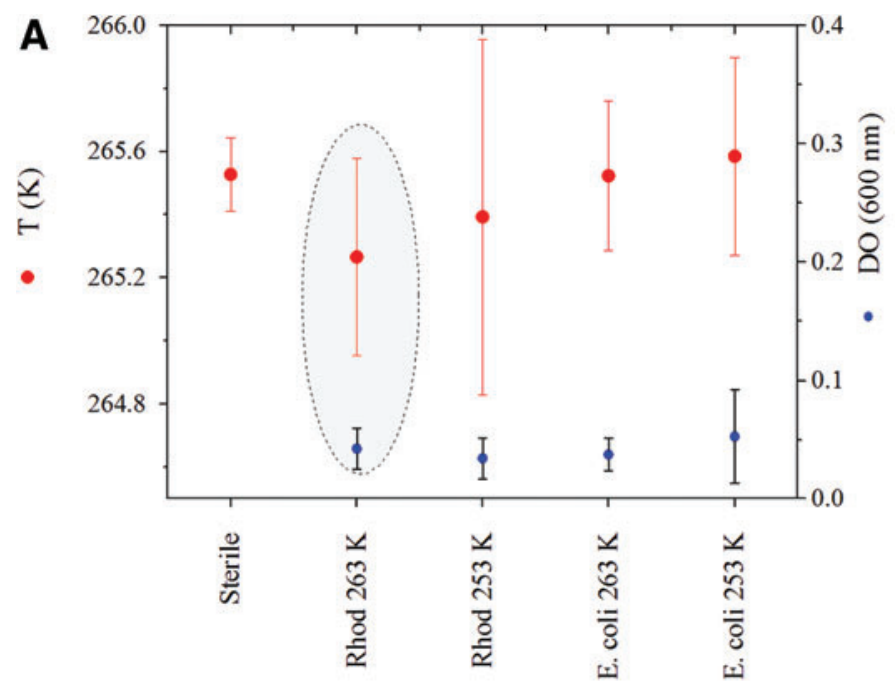

FIG. 1. (A) Experimental data for the $20 \mathrm{wt} \%$ solution (red points), together with the optical density at $600 \mathrm{~nm}$ of the cultures (blue points), after 10 days at $253 \mathrm{~K}$ and $263 \mathrm{~K}$, plotted against the temperature of the liquidus point (T liquidus melting) recorded by calorimetry. (B) Variation of $\mathrm{TH}(\mathrm{K})$ as a function of the cell concentration in Rhodococcus after 10 days in 20 wt $\% \mathrm{Mg}\left(\mathrm{ClO}_{4}\right)_{2}$, at $253 \mathrm{~K}$ (red circles) and $263 \mathrm{~K}$ (red squares). The blue diamond corresponds to the sterile solution. $\mathrm{TH}$ is normally calculated as the difference between $\mathrm{T}_{\text {onset }}$ freezing and $\mathrm{T}_{\text {onset }}$ congruent melting (Lee et al., 2018), but in the case of perchlorate, we used the $\mathrm{T}_{\text {onset }}$ incongruent melting (see Supplementary Fig. $\mathrm{S} 3$ ). $\mathrm{TH}$, thermal hysteresis. Color images are available online.
B

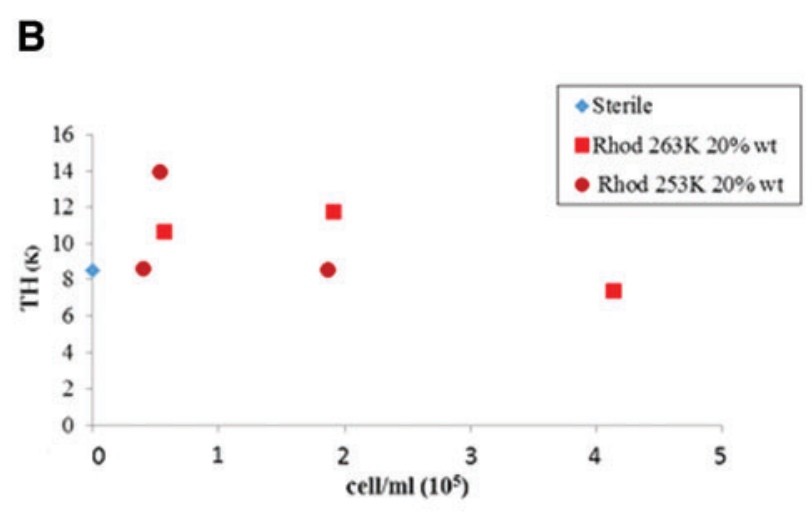

\subsection{Survivability of microorganisms in salty and cold solutions}

We used three different methods to evaluate the survivability of the microorganisms in cold perchlorate solutions: confocal fluorescence microscopy, optical density, and cell reinoculation. Overall, the survivability of bacteria when confronting the two stress conditions tested together (high concentrated salts and subfreezing temperatures) was noticelow (around 2\% in general, and in no case over 4\%), and therefore, it would be more accurate to refer to the "tolerance" of a reduced number of cells to the stress conditions.

Even though the extreme conditions tested triggered a high rate of mortality, flow cytometry analysis still showed a reduced proportion of living cells in the two species analyzed (Fig. 2A). Although the plot in Fig. 2A shows higher $263 \mathrm{~K}$, these data need to be considered carefully because they came with the caveat of large standard deviations. In addition, when analyzing the tolerance of $E$. coli cells to the imultaneous stress conditions tested here (freezing temtives and including perchlorate), a few live cells were (i. observed, although with changes in their morphology fractions of the cultures of Rhodococcus sp. JG3 were inoculated again into Luria-Bertani broth (LB) tubes, and after 1 month at room temperature, some cells in the reinoculated medium were able to recover.

\subsection{Changes in protein profiles after exposure to cold and salty conditions}

The protein patterns obtained by electrophoresis separation (Fig. 3) show differences between the molecular machinery expressed in the cultures grown in standard conditions (LB medium and optimal growth temperature) and in values of viable cells of $E$. coli than Rhodococcus sp. JG3 at Importantly, at the end of the experimental time (10 days) 
A

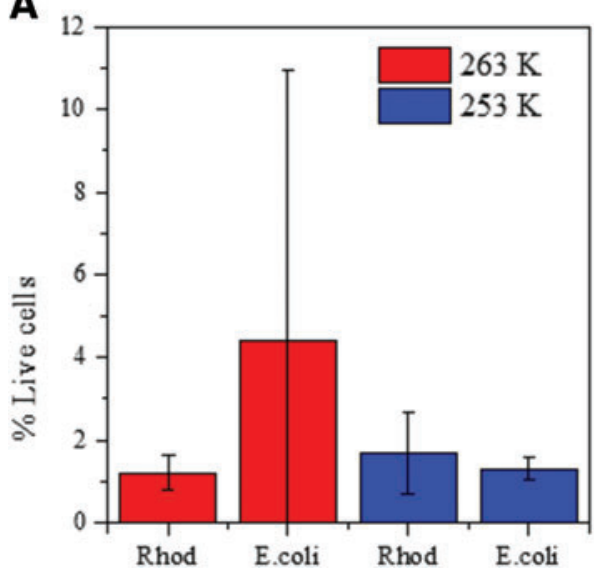

B

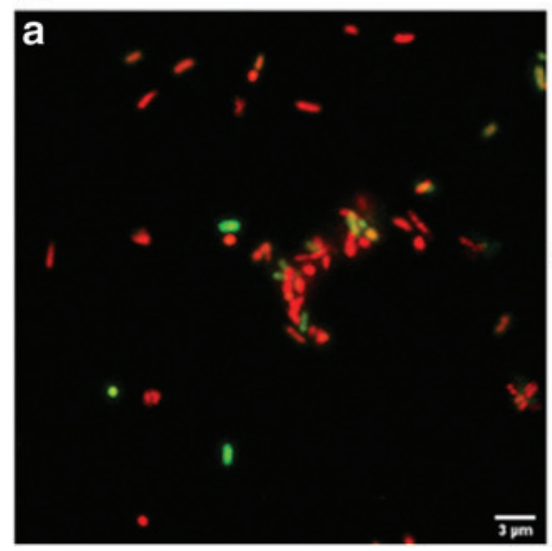

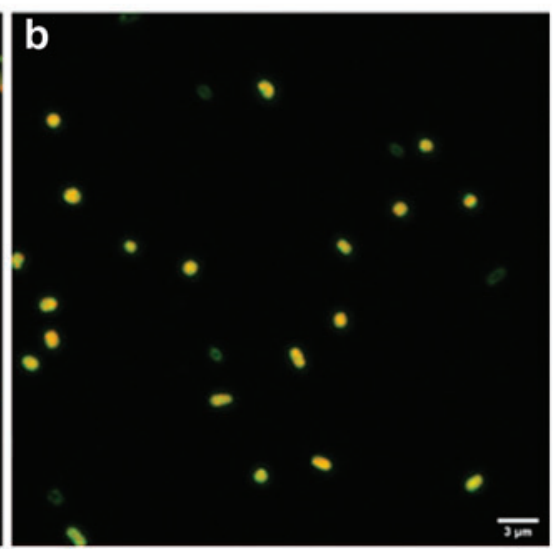

FIG. 2. (A) Relative survival rate of cells (\%) after 10 days of cultivation in $15 \mathrm{~mL}$ of $20 \mathrm{wt} \%$ magnesium perchlorate at $263 \mathrm{~K}$ and $253 \mathrm{~K}$, as determined by flow cytometry using propidium iodide as the staining agent. The shift was from $10^{5}$ cells $/ \mathrm{mL}$ of initial concentration to $10^{3}$ cell/ $/ \mathrm{mL}$ of survival. (B) Confocal microscopy images of cell cultures in perchlorate after 10 days at temperatures of $263 \mathrm{~K}$ and $253 \mathrm{~K}$ : (a) Rhodococcus sp. JG3 and (b) Escherichia coli living cells are highlighted in green, dead cells in red, and cells with compromised membranes (i.e., permeable to propidium iodide) in yellow. The images show a high proportion of dead Rhodococcus sp. JG3 cells, but still some living bacteria could be appreciated. Microscopy imagery revealed that the size and shape of E. coli seemed to be slightly modified after the exposure to the cold and salty stress conditions. Color images are available online.

stressed conditions [including $20 \mathrm{wt} \% \mathrm{Mg}\left(\mathrm{ClO}_{4}\right)_{2}$, and at $263 \mathrm{~K}]$. Comparing the electrophoresis patterns, we observed that there are some proteins overexpressed and some underexpressed in the stressed cultures compared with the optimal cultures. Therefore, bacteria were probably using or synthetizing those proteins, among other molecules used for adaptation, to cope with or adapt to the stressing environmental factors. Some of these differences can be observed in Fig. 3, where the protein pattern expressed by Rhodococcus sp. JG3 in cold perchlorate includes, among others, two protein bands with a molecular weight around $21 \mathrm{kDa}$ and another around $50 \mathrm{kDa}$, which did not appear previously in the profile of the extract from optimal conditions.

\section{Discussion}

\subsection{The physicochemical state of the brine environment}

We observed that calorimetry could be a promising method to analyze potential changes in the phase transition behavior of perchlorate solutions possibly caused by the presence of bacterial cultures at subfreezing temperatures. We tested the bacterial behavior in two different regions of the phase diagram of the $\mathrm{H}_{2} \mathrm{O}-\mathrm{Mg}\left(\mathrm{ClO}_{4}\right)_{2}$ binary system (Chevrier et al., 2009; Hanley and Chevrier, 2009; Hanley et al., 2009), below $(20 \mathrm{wt} \%)$ and above (50 wt \%) the eutectic composition, respectively (Toner and Catling, 2016). However, the system that formed between the water-perchlorate and the whole cells-the survivors and the dead-and provided sets of molecules to the medium constitutes a highly complex and uncontrolled arrangement that should be further studied by controlling, step by step, one variable at a time.

We could not establish a clear relationship between cell concentration (living and dead) in the cultures in perchlorate solutions and the changes observed in $\mathrm{TH}$ calculated from thermograms (Fig. 1B). Further experiments specifically focused on that potential relationship will be required for future work, as will better controls with regard to the metastability of the salt. It is likely that the gap observed is due to the perchlorate and high solute concentration, and the contribution of cells likely remains low in our experiments and may be shielded by the effect of the salt. Presumably, the concentration of cells, and thus the potential molecules and components affecting the solution, is noticeably lower compared with the salt concentration.

\subsection{Bacterial IBPS}

The protein profile from the extracts of cultures of Rhodococcus sp. JG3 at $263 \mathrm{~K}$ in $20 \mathrm{wt} \%$ of magnesium perchlorate (Fig. 3) constitutes a first insight into the proteomic analysis of the responses of this bacterium to cold and salty (particularly perchlorates) conditions. Our result that shows a shift in the liquidus point of $0.4 \mathrm{~K}$ (Fig. 1A) in the Rhodococcus sp. JG3 cultures falls again within the experimental error. However, when we compared the obtained values in the Rhodococcus sp. JG3 cultures with those obtained with E. coli, the question remains as to whether the presence of Rhodococcus sp. JG3 could have a modifying effect over the freezing point/properties of the water component of the perchlorate system, an effect that is not occurring in the case of E. coli. This was our starting hypothesis, and after this first attempt at verification, we can only present a null result here. Still, we hypothesize that this effect, pending corroboration with additional experiments, would arise as a result of the molecular response of this bacterium to cope with the stressful conditions, maybe using IBPs or other possible molecules.

Several examples of how IBPs work support this idea. The EfcIBPs from the Antarctic bacteria consortium have both $\mathrm{TH}$ and ice recrystallization inhibition activities to control the formation and growth of ice crystals, which contribute to the survival at subzero temperatures (Mangiagalli et al., 2018). Other microorganisms that live in icy habitats 


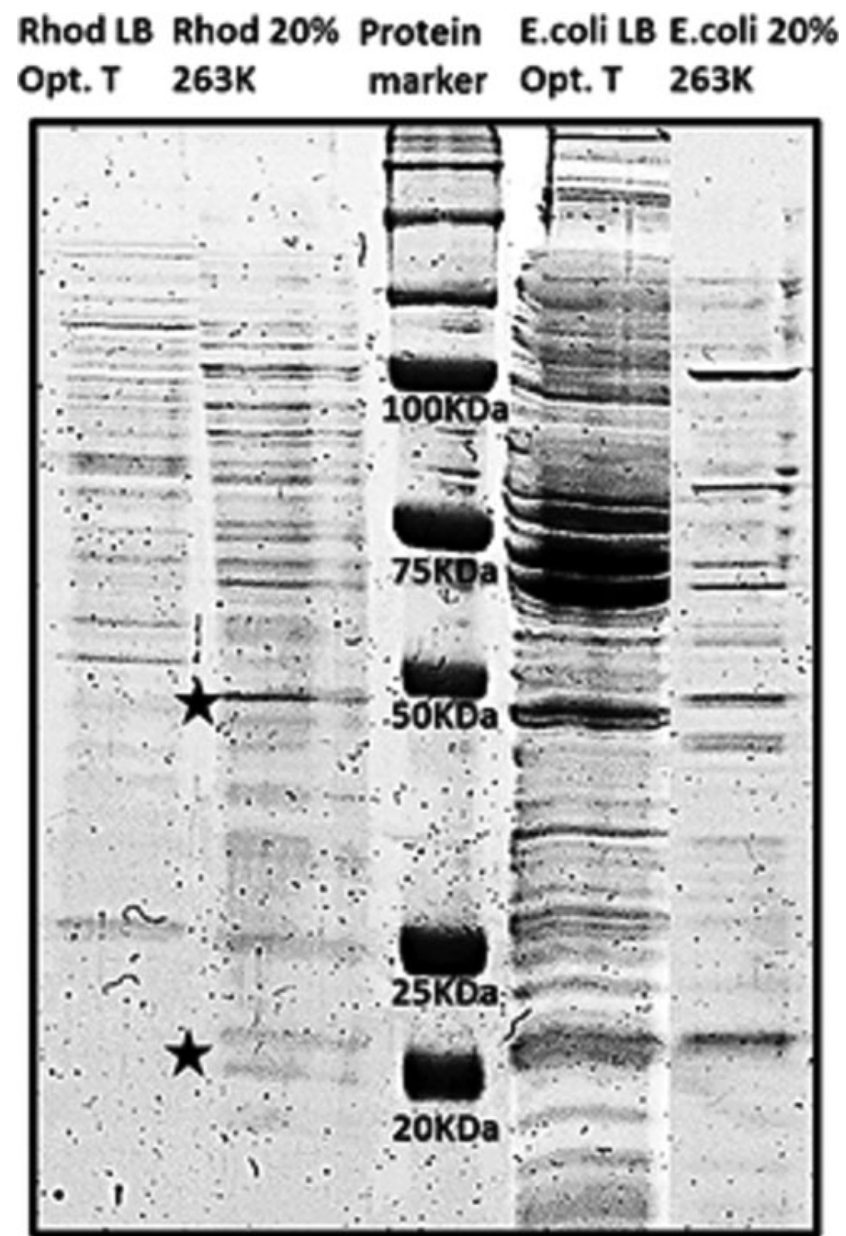

FIG. 3. Comparison of electrophoretic banding patterns of protein extracts between cultures of Rhodococcus sp. JG3 and Escherichia coli in LB at optimal temperature, with those in $20 \mathrm{wt} \% \mathrm{Mg}\left(\mathrm{ClO}_{4}\right)_{2}$ cultivated at $263 \mathrm{~K}$. Central lane (Protein marker) is the known pattern of a protein standard (Precision Plus Protein ${ }^{\mathrm{TM}}$ All Blue Prestained Protein Standards; Bio-Rad), which main molecular weights are indicated on the right $(\mathrm{kDa})$. Black stars show examples of proteins in Rhodococcus sp. JG3 overexpressed at $263 \mathrm{~K}$ in $20 \mathrm{wt} \% \mathrm{Mg}\left(\mathrm{ClO}_{4}\right)_{2}$. LB, Luria-Bertani broth.

secrete IBPs to the extracellular environment and, by blocking ice formation, keep water channels open in the surrounding ice for respiration, reproduction, and nutrient uptake (Raymond and Kim, 2012; Davies, 2014). The psychrophile and halophile Marinomonas primoryensis (Bar Dolev and Braslavsky, 2017) uses its MpIBP to bind with the ice, purportedly to keep the cell in the upper frozen layer of the water column where oxygen and nutrients are more abundant; moreover, this $M p$ IBP could promote a favorable microenvironment for other nearby microorganisms, which suggests a biofilm-forming role for this protein.

Broadening these proteomic studies could inform with regard to the responsible contributors of the interaction between the cells and the perchlorate system and other proteins that are differentially expressed and involved in cell functions in the cold salty conditions, such as some members of the Csp family that also play a role in osmotic stress (Phadarte, 2004; Schmid et al., 2009). Nevertheless, it is promising to note the over- and underexpression of some proteins in the Rhodococcus sp. JG3 at $263 \mathrm{~K} 20 \mathrm{wt} \%$ $\mathrm{Mg}\left(\mathrm{ClO}_{\mathrm{a}}\right)_{2}$, in contrast with the optimal conditions that could be IBPs and/or other frequent cold-adaptation proteins such as Csp, among others. For instance, regarding the bands of 21 and $50 \mathrm{kDa}$, as previously indicated (Fig. 3), there are a lot of different reported examples of proteins around $21 \mathrm{kDa}$ (including some IBPs, and cold shock domains [CSDs], such as the IBP of the Antarctic bacterium Shewanella frigidimarina [SfIBP1]), that contain a common domain to many IBPs, namely, the DUF3494 domain of around $\sim 25 \mathrm{kDa}$ (Vance et al., 2018) or the putative $21 \mathrm{kDa}$ protein, which contains two CSDs in Caulobacter crescentus (Lang and Marques, 2004). One example of IBPs of a molecular weight close to the $50 \mathrm{kDa}$ band is a $52 \mathrm{kDa}$ lipoprotein of Moraxella sp. strain from Antarctica with antifreeze activity that alters ice crystals into a hexagonal shape (Yamashita et al., 2002). However, other proteins have the molecular weights highlighted by the sodium dodecyl sulfate-polyacrylamide gel electrophoresis (SDS-PAGE), even in E. coli extracts (Fig. 3), and some of them are involved in general stress responses or even in osmotic stress response, as is the case of sigma factors (Okada et al., 2006; Melnyk et al., 2011).

\subsection{The effect of cold and salty conditions on the survivability of bacteria}

The study of the combined cold and salty conditions bears an extra relevance, beyond the understanding of the central role of IBPs, because relatively often the molecules synthetized by bacteria to cope with both conditions are the same, as is the case, for example, of the synthesis of trehalose and other compatible osmotic solutes (De Maayer et al., 2014; Cray et al., 2015). Previous work has reported the survivability rates of different species of bacteria in perchlorate solutions, at different temperatures and for different periods of time (Al Soudi et al., 2017; Heinz et al., 2018, 2019), but to the best of our knowledge, no previous reports have studied the combined effect of several conditions relevant to Mars, including (1) high concentration of magnesium perchlorate in solution, (2) subfreezing incubation temperatures, and (3) medium-long incubation times, as we have considered in this study. The results of our Marsrelevant experiments show that although the majority of the cells in the analyzed cultures died after exposure to freezing temperatures and high concentrations of perchlorates, as expected, some cells remained viable in the solutions (Fig. 2), and they were even able to recover after the optimal growth conditions were restored.

The limits of growth in perchlorate for Rhodococcus remain unknown, but several studies of other halotolerant microorganisms indicate tolerance and growth at concentrations up to $20 \%$ in a nonperchlorate salt $(\mathrm{NaCl})$. Growth is reduced (around 2\%) in the case of magnesium perchlorate, but it increases if both salts are combined in the medium (Matsubara et al., 2017). On the contrary, Al Soudi et al. (2017) established a minimum growth of the halotolerant Halomonas venusta (HL12) in a medium supplemented with a $10 \%$ of magnesium perchlorate that was near the threshold chosen for faint growth (0.1 OD unit). These data are in agreement with the relative survival rate observed in our Rhodococcus sp. JG3cultures (Fig. 2A). 
Specifically, as described in Section 3, when Rhodococcus $\mathrm{sp}$. JG3 was reinoculated in LB media and at optimal temperature after the exposure to perchlorate and subfreezing temperatures, a significant increment of biomass was observed. This suggests that the few surviving cells, detected by cytometry and observed with confocal microscopy, kept their ability to multiply when optimal environmental conditions were restored. This is in agreement with results of previous studies where microbes and other organisms were found to be able to enter into a kind of standby mode (stasis) (Mackenzie et al., 1977; Junge et al., 2004; Storey and Storey, 2004) and recover upon warming to the restored conditions of temperature that allows water to reach a liquid state. Sun et al. (1995) reported a recovery of Pseudomonas putida GR12, after a short incubation at 253 $\mathrm{K}$ and $223 \mathrm{~K}$ during $24 \mathrm{~h}$, when optimal conditions were restored. A reversible response of the chaotropic effects on cells observed in our experiments has been reported as well in fungi studies (Williams and Hallsworth, 2009), and Hydrogenothermus marinus, a thermophilic bacterium with a morphology that can be affected by the presence of perchlorates, is reversed back to its original nonaggregated shape when it is cultured again in a medium without perchlorates (Beblo-Vranesevic et al., 2017). These morphological changes of bacteria and their aggregation in the perchlorate solutions have been recently described as well for Planococcus halocryophilus as a salt stress response (Heinz et al., 2019), and have also been observed in our Rhodococcus cultures in $\mathrm{Mg}\left(\mathrm{ClO}_{4}\right)_{2}$ (Fig. 2B).

Regarding the tolerance of $E$. coli cells to both stress conditions simultaneously (cold and perchlorate), we detected moderate living biomass and a change in the morphology of cells from the rod shape to a more spherical one. We cannot exclude the possibility of an overestimation of the survivability of $E$. coli due to these changes in morphology that differed from the normal shape of cells in the control culture and used to establish the cytometry settings for measures; and even the yellow color of these more spherical cells, which indicates an intermediate stage on the path to death, could have contributed to this overestimation. Several reports have shown that bacterial morphological changes are indeed caused by environmental stress conditions (Shen and Chou, 2016), which happens especially in salty media and at low temperatures for gram-negative bacteria such as E. coli (Yang et al., 2016). In particular, different types of bacteria tolerant to high perchlorate concentrations became larger and morphologically aberrant (Oren et al., 2014), or aggregated into long cellular chains (Beblo-Vranesevic et al., 2017), when exposed to this salt. The effect of perchlorates on the morphology of methanogenic archaea has also been reported (Shcherbakova et al., 2015).

\subsection{Implications for the habitability of martian perchlorate solutions}

Although the specific roles of IBPs as extreme adaptive strategies of microorganisms to cold temperatures are well known and have been extensively exploited in many biotechnological applications over the last decade (Lorv et al., 2014), little is known about their implications in astrobiology and on the search for life elsewhere in the solar sys- tem. Here, we hypothesize that some proteins such as the IBPs - and possibly others, including some similar to Csp that may act as if they were "cold-brine shock proteins"could help to modify the microenvironment around microorganisms to achieve conditions of enhanced habitability where and when water availability is a key factor, as seems to be the case for Mars during most (if not all) its geological history (Fairén, 2010).

We hypothesize that the physical presence of bacteria capable to cope with cold and salty conditions may have an influence on cold brines, providing favorable scenarios for the formation of microniches where life would be possible. Average temperatures typical for the winter at low- and midlatitudes on Mars are in the range of 220-250 K (Möhlmann and Thomsen, 2011; Martínez et al., 2017), therefore overlapping with the lowest temperature described compatible with active metabolism of bacterium such as P. halocryophilus Or1 at $248 \mathrm{~K}$ (Mykytczuk et al., 2013), or others from the Antarctic glacial isolate bacteria at $240 \mathrm{~K}$ (Bakermans and Skidmore, 2011). The lowest temperature at which Rhodococcus keeps metabolically active has been established at $258 \mathrm{~K}$ (Goordial et al., 2015), close enough to that of the formation of perchlorate brines. Therefore, we wonder if, in the path to freezing temperatures-and even if not succeeding in terms of cellular division-the molecular machinery activated could modify to some extent the microenvironment of the brines to make them potentially more habitable, at least in a very slow pace and in the long term. Our goal is to obtain a better understanding about the strategies that microorganisms could have been able to adopt in Mars-analog environments on the Earth, as a way to help guide the search for specific biomarkers on Mars.

\subsection{Ongoing/future work}

The hypothesis presented here opens new perspectives with which to explore more deeply those mechanisms microorganisms use to adapt to stressors in microenvironments, and it will aid in our understanding whether, as a result of adaptation, microorganisms can influence extreme cold and salty environments and make them more hospitable. To test the hypothesis presented here and complement this work, a modification of the incubation times and an increase in the number of samples and the amount of biomass used would be required. Further development in this new area of research would also require the following: (1) extending our experiments to a variety of halophilic archaea; bacteria; relevant eukaryotes (e.g., Antarctic cryptoendolithic lichens); other aerobic psychrophilic strains, in particular, in which IBPs have been recently described in detail; and anaerobic cultures where perchlorates can act as electron acceptors; (2) extending our analyses by using different salt components; (3) incorporating additional assays of the potential changes in the eutectic point of different salts influenced by the presence of microorganisms and, as a result, the changes in the adaptation of the microorganisms to salinity and at different subzero temperatures, as well as temperature cycles that may act as triggering factors for the synthesis of IBPs; (4) identifying and isolating IBPs and the search for other proteins produced by microorganisms in different salt solutions at freezing temperatures and at different concentrations in 
calorimetry experiments; (5) studying in detail the effect of vitrification on bacteria and on the proteins expressed by them; and (6) from these studies and along additional proteomic analyses, identifying new biomarkers to be considered for the astrobiological exploration of Mars and other planetary bodies.

\section{Conclusions}

We have presented here the novel question of whether microorganisms can change the freezing/melting curve of perchlorate (or any salt) solutions. Our study has implications with regard to our understanding of the potential habitability of brines on Mars, given that the ability to extend the liquid phase by protein expression could offer an ecological advantage for organisms on Earth and on Mars. We tried to verify our hypothesis by identifying a suitable candidate and testing it. However, we did not find any definitive effect on phase transitions, despite the evidence of a change in protein expression and reduced survivability. The fact that the specific combination of bacteria (Rhodococcus sp. JG3) and salt (cold Mg-perchlorate solutions) tested did not show the expected effect means that we can only report in this article a null result in testing our hypothesis, although the question remains an interesting one and deserves further examination. We plan to continue the search for proteins produced by microorganisms that inhabit very cold and highly saline solutions to determine whether there are any effects on the liquid-to-ice transition. Our plans include testing halophilic archaea, bacteria, and some relevant eukaryotes (such as Antarctic cryptoendolithic lichens) by using different salt components.

Future results achieved by further experiments could provide meaningful insight as to the impact microbial life may have had in the past on Mars and throughout the planet's evolution. The possibility that certain microorganisms could modulate their environments to some extent by influencing the chemical properties of the aqueous phases, and therefore providing favorable microniches that support their survival, constitutes an intriguing path by which to explore the hypothesis of the existence of self-regulating complex biogeological systems with feedback mechanisms (Lovelock and Margulis, 1974), which may be applicable to life on Earth and potentially on Mars.

\section{Acknowledgments}

Special thanks to Sylvia Gutiérrez Erlandsson and Ana Oña Blanco from the Advance Light Microscopy service, and Maria del Carmen Moreno-Ortiz from the Flow Cytometry service, both at Centro Nacional de Biotecnología (CNB, Madrid), for their assistance and advice. The strain of Rhodococcus sp. JG-3 used here was courteously donated by Lyle White (McGill University). Chris McKay provided critical guidance for the presentation of our results. The comments by two anonymous reviewers are appreciated.

\section{Author Disclosure Statement}

No competing financial interests exist.

\section{Funding Information}

The research leading to these results is a contribution from the Projects "icyMARS" and "MarsFirstWater," funded by the European Research Council, Starting grant number 307496 and Consolidator grant number 818602, respectively, to A.G.F. V.M.I. and O.P.B. acknowledge funding from the Spanish MINECO projects ESP201455811-C2-1-P and ESP2017-89053-C2-1-P, respectively. We acknowledge support from the AEI project number MDM-2017-0737 Unidad de Excelencia "Marı́a de Maeztu" to C.A.B.

\section{Supplementary Material}

Supplementary Data

Supplementary Figure S1

Supplementary Figure S2

Supplementary Figure S3

\section{References}

Al Soudi AF, Farhat O, Chen F, et al. (2017) Bacterial growth tolerance to concentrations of chlorate and perchlorate salts relevant to Mars. Int J Astrobiol 16:229-235.

Bakermans C and Skidmore M (2011) Microbial respiration in ice at subzero temperatures $\left(-4^{\circ} \mathrm{C}\right.$ to $\left.-33^{\circ} \mathrm{C}\right)$. Environ Microbiol Rep 3:774-782.

Bar Dolev M and Braslavsky I (2017) Ice-binding proteins-not only for ice growth control. Temperature (Austin) 4:112-113.

Beblo-Vranesevic K, Huber H, and Rettberg P (2017) High tolerance of Hydrogenothermus marinus to sodium perchlorate. Front Microbiol 8:1369.

Celik Y, Graham LA, Mok Y-F, et al. (2010) Superheating of ice crystals in antifreeze protein solutions. Proc Natl Acad Sci U S A 107:5423-5428.

Chevrier VF, Hanley J, and Altheide TS (2009) Stability of perchlorate hydrates and their liquid solutions at the Phoenix landing site, Mars. Geophys Res Lett 36. Available online at https://agupubs.onlinelibrary.wiley.com/doi/full/10.1029/2009 GL037497

Cochet N and Widehem P (2000) Ice crystallization by Pseudomonas syringae. Appl Microbiol Biotechnol 54:153-161.

Cray JA, Stevenson A, Ball P, et al. (2015) Chaotropicity: a key factor in product tolerance of biofuel-producing microorganisms. Curr Opin Biotechnol 33:228-259.

Davies PL (2014) Ice-binding proteins: a remarkable diversity of structures for stopping and starting ice growth. Trends Biochem Sci 39:548-555.

Davila AF, Duport LG, Melchiorri R, et al. (2010) Hygroscopic salts and the potential for life on Mars. Astrobiology 10 : 617-628.

De Maayer P, Anderson D, Cary C, et al. (2014) Some like it cold: understanding the survival strategies of psychrophiles. EMBO Rep 15:508-517.

Fairén AG (2010) A cold and wet Mars. Icarus 208:165-175.

Fairén AG (2020) Organic chemistry on a cool and wet early Mars. Nature Astron 4:446-447.

Gibout S, Franquet E, Haillot D, et al. (2018) Challenges of the usual graphical methods used to characterize phase change materials by differential scanning calorimetry. Appl Sci 8:66.

Gill P, Moghadam TT, and Ranjbar B (2010) Differential scanning calorimetry techniques: applications in biology and nanoscience. J Biomol Tech 21:167-193.

Glavin DP, Freissinet C, Miller KE, et al. (2013) Evidence for perchlorates and the origin of chlorinated hydrocarbons detected by SAM at the Rocknest aeolian deposit in Gale Crater. J Geophys Res Planets 118:1955-1973. 
Goordial J, Raymond-Bouchard I, Zolotarov Y, et al. (2015) Cold adaptive traits revealed by comparative genomic analysis of the eurypsychrophile Rhodococcus sp. JG3 isolated from high elevation McMurdo Dry Valley permafrost, Antarctica. FEMS Microbiol Ecol 92:fiv154.

Gough RV, Chevrier VF, Baustian KJ, et al. (2011) Laboratory studies of perchlorate phase transitions: support for metastable aqueous perchlorate solutions on Mars. Earth Planet Sci Lett 312:371-377.

Hanley JE and Chevrier VF (2009) Hydrous perchlorates and their relation to humidity at the Phoenix Landing Site. In New Martian Chemistry Workshop, LPI Contribution No. 1502, Lunar and Planetary Institute, Houston, p. 15.

Hanley J, Chevrier VF, and Altheide TS (2009) Low temperature aqueous perchlorate solutions on the surface of Mars. In 40th Lunar and Planetary Science Conference, Houston, TX, USA. Available online at https://www.lpi.usra.edu/ meetings/lpsc2009/pdf/1380.pdf

Hansen TN and Baust JG (1988) Differential scanning calorimetric analysis of antifreeze protein activity in the common mealworm, Tenebrio molitor. Biochim Biophys Acta 957: 217-221.

Hecht MH, Kounaves SP, Quinn RC, et al. (2009) Detection of perchlorate and the soluble chemistry of martian soil at the Phoenix Lander Site. Science 325:64-67.

Heinz J, Schirmack J, Airo A, et al. (2018) Enhanced microbial survivability in subzero brines. Astrobiology 18:1171-1180.

Heinz J, Waajen AC, Airo A, et al. (2019) Bacterial growth in chloride and perchlorate brines: halotolerances and salt stress responses of Planococcus halocryophilus. Astrobiology 19: 1377-1387.

Hirano SS and Upper CD (2000) Bacteria in the leaf ecosystem with emphasis on Pseudomonas syringae - a pathogen, ice nucleus, and epiphyte. Microbiol Mol Biol Rev 64:624-653.

Junge K, Eicken H, and Deming JW (2004) Bacterial Activity at -2 to -20 degrees $\mathrm{C}$ in Arctic wintertime sea ice. Appl Environ Microbiol 70:550-557.

Kajava AV, Steven E, and Lindow SE (1993) A model of the three-dimensional structure of ice nucleation proteins. $J \mathrm{Mol}$ Biol 232:709-717.

Knight CA (2000) Adding to the antifreeze agenda. Nature 406: 249-251.

Krell A, Beszteri B, Dieckmann G, et al. (2008) A new class of ice-binding proteins discovered in a salt-stress-induced cDNA library of the psychrophilic diatom Fragilariopsis cylindrus (Bacillariophyceae). Eur J Phycol 43:423-433.

Lang EAS and Marques MV (2004) Identification and transcriptional control of Caulobacter crescentus genes encoding proteins containing a cold shock domain. J Bacteriol 186: 5603-5613.

Lee S, Lee JH, Kim H-W, et al. (2018) Properties of phase transition of ice binding protein from Arctic yeast (LeIBP) utilizing differential scanning calorimetry (DSC) and Raman spectroscopy. Cryobiology 85:33-38.

Lorv JSH, Rose DR, and Glick BR (2014) Bacterial ice crystal controlling proteins. Scientifica 2014:20.

Lovelock JE and Margulis L (1974) Atmospheric homeostasis by and for the biosphere: the Gaia hypothesis. Tellus 26:2-10.

Mackenzie AP, Derbyshire W, Reid DS, et al. (1977) Nonequilibrium freezing behaviour of aqueous systems. Phil Trans R Soc Lond B Biol Sci 278:167-189.

Maki LR, Galyan EL, Chang-Chien MM, et al. (1974) Ice nucleation induced by Pseudomonas syringae. Appl Microbiol 28:456-459.
Mangiagalli M, Sarusi G, Kaleda A, et al. (2018) Structure of a bacterial ice binding protein with two faces of interaction with ice. FEBS $J$ 285:1653-1666.

Martínez GM, Newman CN, De Vicente-Retortillo A, et al. (2017) The modern near-surface martian climate: a review of in-situ meteorological data from Viking to curiosity. Space Sci Rev 212:295-338.

Martín-Torres FJ, Zorzano M-P, Valentín-Serrano $\mathrm{P}$, et al. (2015) Transient liquid water and water activity at Gale Crater on Mars. Nat Geosci 8:357.

Matsubara T, Fujishima K, Saltikov C, et al. (2017) Earth analogues for past and future life on Mars: isolation of perchlorate resistant halophiles from Big Soda Lake. Int J Astrobiol 16:218-228.

Melnyk RA, Engelbrektson A, Clark IC, et al. (2011) Identification of a perchlorate reduction genomic island with novel regulatory and metabolic genes. Appl Environ Microbiol 77: 7401-7404.

Möhlmann D and Thomsen K (2011) Properties of cryobrines on Mars. Icarus 212:123-130.

Mykytczuk NCS, Foote SJ, Omelon CR, et al. (2013) Bacterial growth at $-15^{\circ} \mathrm{C}$; molecular insights from the permafrost bacterium Planococcus halocryophilus Or1. ISME J 7:12111226.

Ojha L, Wilhelm MB, Murchie SL, et al. (2015) Spectral evidence for hydrated salts in recurring slope lineae on Mars. Nat Geosci 8:829.

Okada Y, Okada N, Makino S-i, et al. (2006) The sigma factor RpoN $(\sigma 54)$ is involved in osmotolerance in Listeria monocytogenes. FEMS Microbiol Lett 263:54-60.

Oren A, Elevi Bardavid R, and Mana L (2014) Perchlorate and halophilic prokaryotes: implications for possible halophilic life on Mars. Extremophiles 18:75-80.

Phadarte S (2004) Recent developments in bacterial cold-shock response. Curr Issues Mol Biol 6:125-136.

Rapin W, Ehlmann BL, Dromart G, et al. (2019) An interval of high salinity in ancient Gale Crater lake on Mars. Nat Geosci 12:889-895.

Raymond JA and DeVries AL (1977) Adsorption inhibition as a mechanism of freezing resistance in polar fishes. Proc Natl Acad Sci U S A 74:2589-2593.

Raymond JA and Kim HJ (2012) Possible role of horizontal gene transfer in the colonization of sea ice by algae. PLoS One 7:e35968.

Robertson K and Bish D (2011) Stability of phases in the $\mathrm{Mg}(\mathrm{ClO} 4) 2 \cdot \mathrm{nH} 2 \mathrm{O}$ system and implications for perchlorate occurrences on Mars. J Geophys Res Planets 116. Available online at https://agupubs.onlinelibrary.wiley.com/doi/full/10 .1029/2010JE003754

Schmid B, Klumpp J, Raimann E, et al. (2009) Role of cold shock proteins in growth of Listeria monocytogenes under cold and osmotic stress conditions. Appl Environ Microbiol 75:1621-1627.

Shcherbakova V, Oshurkova V, and Yoshimura Y (2015) The effects of perchlorates on the permafrost methanogens: implication for autotrophic life on Mars. Microorganisms 3:518-534.

Shen J-P and Chou C-F (2016) Morphological plasticity of bacteria-Open questions. Biomicrofluidics 10: 031501.

Stillman DE and Grimm RE (2011) Dielectric signatures of adsorbed and salty liquid water at the Phoenix landing site, Mars. J Geophys Res Planets 116. Available online at https:// agupubs.onlinelibrary.wiley.com/doi/full/10.1029/2011JE003838

Storey JM and Storey KB (2004) Cold hardiness and freeze tolerance. In: Functional Metabolism: Regulation and 
Adaptation, edited by KB Storey, John Wiley \& Sons, Hoboken, NJ, Canada.

Sun X, Griffith M, Pasternak JJ, et al (1995) Low temperature growth, freezing survival, and production of antifreeze protein by the plant growth promoting rhizobacterium Pseudomonas putida GR12-2. Can J Microbiol 41:776-784.

Sutter B, McAdam AC, Mahaffy PR, et al. (2017) Evolved gas analyses of sedimentary rocks and eolian sediment in Gale Crater, Mars: results of the Curiosity rover's sample analysis at Mars instrument from Yellowknife Bay to the Namib Dune. J Geophys Res Planets 122:2574-2609.

Thomas NH, Ehlmann BL, Meslin P-Y, et al. (2019) Mars Science Laboratory observations of chloride salts in Gale Crater, Mars. Geophys Res Lett 46:10754-10763.

Toner JD and Catling DC (2016) Water activities of $\mathrm{NaClO}_{4}$, $\mathrm{Ca}\left(\mathrm{ClO}_{4}\right)_{2}$, and $\mathrm{Mg}\left(\mathrm{ClO}_{4}\right)_{2}$ brines from experimental heat capacities: water activity $>0.6$ below 200K. Geochim Cosmochim Acta 181:164-174.

Toner JD, Catling DC, and Light B (2014) The formation of supercooled brines, viscous liquids, and low-temperature perchlorate glasses in aqueous solutions relevant to Mars. Icarus 233:36-47.

Vance TDR, Graham LA, and Davies PL (2018) An ice-binding and tandem beta-sandwich domain-containing protein in Shewanella frigidimarina is a potential new type of ice adhesin. FEBS J 285:1511-1527.

Williams JP and Hallsworth JE (2009) Limits of life in hostile environments: no barriers to biosphere function? Environ Microbiol 11:3292-3308.

Yamashita Y, Nakamura N, Omiya K, et al. (2002) Identification of an antifreeze lipoprotein from Moraxella sp. of Antarctic origin. Biosci Biotechnol Biochem 66:239-247.
Yang DC, Blair KM, and Salama NR (2016) Staying in shape: the impact of cell shape on bacterial survival in diverse environments. Microbiol Mol Biol Rev 80: 187-203.

Zorzano M-P, Mateo-Martí E, Prieto-Ballesteros O, et al. (2009) Stability of liquid saline water on present day Mars. Geophys Res Lett 36. Available online at https://agupubs .onlinelibrary.wiley.com/doi/full/10.1029/2009GL040315

Address correspondence to: Alberto G. Fairén Centro de Astrobiología (CSIC-INTA)

$M-108, \mathrm{~km} 4$ Madrid 28850

Spain

E-mail: agfairen@cab.inta-csic.es

Submitted 13 May 2019

Accepted 24 June 2020 Associate Editor: Christopher McKay 